\title{
Possible use of BHT to estimate carcass fat content in small ruminants
}

\author{
E.C. Webb ${ }^{\#}$, K. Steenkamp and E.B. Spreeth \\ Dept of Animal and Wildlife Sciences, University of Pretoria, Pretoria 0002 \\ "Email:ecwebb@positino.up.ac.za
}

\section{Introduction}

Roughly 30 techniques to estimate the composition of live animals or carcasses are described in the literature (Topel \& Kauffman, 1988). Most of the traditional techniques are based on dissections of the whole body postslaughter, followed by proximate analyses. In fact, an absolute measurement of body composition is only possible by dissection of the whole body, followed by chemical analyses. The latter procedure is a rather tedious and expensive approach. Non-destructive methods to estimate body composition include live weight, body density, total body water, total body potassium, skinfold thickness and subcutaneous fat thickness by fat probes. The more recent developments (ultrasonic scanning, bioelectrical impedance analysis, total body electrical conductivity, dual energy $\mathrm{X}$-ray absorptiometry, computer assisted tomography and nuclear magnetic resonance imaging) are generally too expensive for practical application in domestic animals (Webb et al., 1997). Although carcass fat content correlates with the thickness and fatty acid content of subcutaneous fat, the correlations are variable. butylated hydroxytoluene (BHT) is routinely included in fatty acid analyses as antioxidant (Webb et al., 1994), and the aim of this paper is to report on the possible use of BHT to estimate carcass fat content in domestic animals.

\section{Materials and Methods}

Carcass composition data (proximate analyses of the right side of each carcass, fatty acid profile and BHT content of subcutaneous fat) were obtained for Dorper and SA Muttton Merino wethers and castrated goats. Carcass and long-chain fatty acid composition of the different species were analysed (Webb \& Casey, 1995). BHT was included at a concentration of $0,1 \%$ with chloroform in the extraction procedure. Analysis of variance (ANOVA), as well as correlation and simple regression analyses were performed (SAS, 1992).

\section{Results and Discussion}

A correlation coefficient of $-0,84$ was obtained between the proportion of BHT and the carcass fat content of the different sheep and goat breeds (pooled data). The results suggest that approximately $72 \%\left(\mathrm{r}^{2}=71,5 \%, \mathrm{P}<\right.$ 0.00001) of the variation in carcass fat content can be explained by the proportion of BHT indicated on the integrator (Figure 1). The exponential model $(y=\exp \cdot[a+b X])$ provided the highest correlation coefficient between the proportion of BHT and carcass fat content (Equation 1):

$$
\mathrm{y}=\exp .(4,42725-0,212759)
$$

The exponential decline in the proportion of BHT with increasing carcass fat content is probably due to the increasing antioxidant activity in samples with a higher fatty acid content. BHT appears to be less sensitive at a carcass fat content of less than 3\% due to the stabilising effect (Webb et al., 1999) of the phospholipids (predominantly unsaturated fatty acids) in the membrane fraction. The use of BHT to estimate carcass fat content in indigenous goats (Equation 2) is considerably more accurate $\left(r=-0,93 ; R^{2}=87 \%\right)$ compared to subcutaneous fat measurements.

$$
\mathrm{y}=\exp \cdot[3,99067-0,158892]
$$




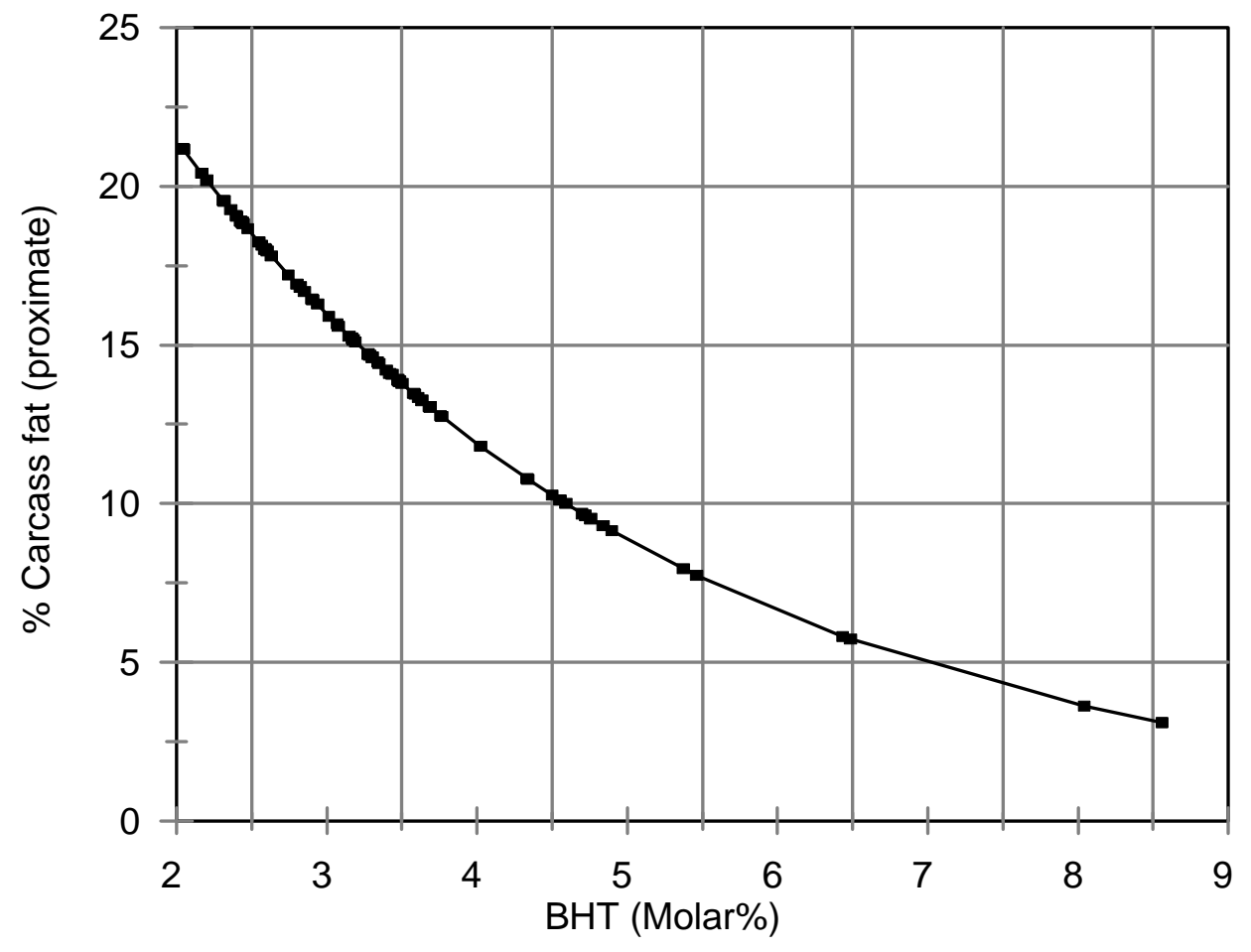

Figure 1. The use of BHT to estimate carcass fat content in small ruminants.

\section{Conclusions}

BHT can be used to estimate carcass fat content in small ruminants. The use of BHT to estimate carcass fat content in indigenous goats is more accurate compared to subcutaneous fat thickness measurements, because of fewer variations due to fat localisation. This technique is not suitable for more accurate estimations as achieved by means of BIA, TOBEC, DXA or NMR.

\section{References}

SAS, 1992. SAS user's guide. Statistical Analysis System Institute Inc., NC.

Topel, D.G. \& Kauffman, R., 1988. Designing foods. National Academy Press, Washington DC, p.258.

Webb, E.C. et al., 1994. Meat Sci., 38, 123.

Webb, E.C. \& Casey, N.H., 1995. Small Rum. Res. 18, 81.

Webb, E.C., 1997. Postdoctoral report, University of Ghent, Belgium.

Webb, E.C. et al., 1998. Meat Sci. 50, 45. 